\title{
Cultural Diversity and the Digital Humanities
}

\author{
Simon Mahony ${ }^{1}$
}

Received: 30 December 2017 / Accepted: 20 February 2018/Published online: 8 March 2018

(C) The Author(s) 2018. This article is an open access publication

\begin{abstract}
Digital humanities has grown and changed over the years; we have moved away from expecting technology to be a tool to make humanities research easier and faster into one where we are now equal partners. Our collaborative projects drive forward the research agendas of both humanists and technologists. There have been other changes too. The focus of our scholarly interest has moved away from its historical origins in text-based scholarship, although that now has many more possibilities, and we are seeing an interest in exploring culture and heritage more widely. Where the progress is slower is in our moves towards openness and inclusivity, and this is to some extent hampered by a lack of linguistic diversity. This is being addressed with specialist groups within the major DH organizations on a national and a global level. DH has grown rapidly in China, and the anglophone world could do more to engage with practitioners and potential colleagues in this new vibrant and emerging area. There are certainly Western centres that specialize, particularly in Chinese texts and historical documents, but this needs to be extended further if we are not to impose limits on the conversations, synergies and collaborations that can result.
\end{abstract}

Keywords Digital humanities · Cultural diversity · Multi-lingualism · Community · Globalism

Simon Mahony

s.mahony@ucl.ac.uk

1 Department of Information Studies, UCL Centre for Digital Humanities, University College London, Gower Street, London WC1E 6BT, UK 


\section{Introduction}

Digital humanities (DH) has grown out of what was previously known as Humanities Computing, and perhaps earlier as Applied Computing in the Humanities, working at the intersection of technology and the humanities. A comprehensive introduction to the growth of $\mathrm{DH}$ can be found in the introductory chapter in Nyhan and Flinn (2016). With this change in nomenclature have come other changes in this versatile and fastmoving interdisciplinary field; the focus has moved away from technology as the servant of the humanities to one where our projects and other activities are of interest to and advance the research agendas of both disciplines. Humanities itself is difficult to define but can, in my view, best be described as the study of the human condition, and of human achievement, and alternatively, as the study of that which makes life worth living. DH commonly works and builds partnerships at the intersection of cultural heritage, human achievement and the computational sciences, exploring new areas that were not possible previously.

This is not the only change that has been occurring. Historically, DH has developed in a very anglophone environment as English became the language of the Internet (with ICANN) and the lingua franca of the Web (with the W3C Consortium), along with the domination of the ASCII code. ICANN is extending things now with the New Generic Top-Level Domains ${ }^{1}$ to include non-Latin characters, although only those that are included in Anglo/US-centric Unicode. ${ }^{2}$ There have been recent studies on the metrics of publication and how that along with citation counts has a clear Anglo-bias, resulting in incentives for advancement, promotion and funding to favour publication in the English language for the Arts and Humanities. ${ }^{3}$ As Domenico Fiormonte argues:

the over-representation of US and UK Humanities titles [as counted in major indices such as Scopus and Web of Science] will always support arguments in favor of using English as the lingua franca, and the misrepresentation of knowledge production and geopolitical imbalance will continue to thrive (Fiormonte 2015).

As he notes, this is supported by metrics from Scopus itself (see Meester 2013).

This article looks at the growth of DH beyond the anglophone sphere and some of the challenges that cross-cultural initiatives present.

The beginnings of $\mathrm{DH}$ are generally ascribed to Roberto Busa and his collaborations with IBM to create an index variorum of the works of Thomas Aquinas, a corpus of Latin texts, although alternatives to the general narrative have been put forward by some scholars. ${ }^{4}$ Nevertheless, Medievalists such as Busa along with Classicists were very much at the forefront of humanities scholars using

\footnotetext{
${ }^{1}$ ICANN https://newgtlds.icann.org.

${ }^{2}$ For this and a cultural critical approach to DH, see Fiormonte (2012).

${ }^{3}$ For more on this, see Crane (2015a) and the response by Fiormonte (2015) and the comments appended to the latter. See also Fiormonte (2012).

${ }^{4}$ See, for example, Rockwell (2007).
} 
computational methodologies for their data-intensive research projects (Bodard and Mahony 2008). Referencing my original discipline of Classics (as referring to Greco-Roman studies), examples would be the Thesaurus Linguae Graecae (TLG) ${ }^{5}$ and the Lexicon of Greek Personal Names (LGPN), ${ }^{6}$ both founded in 1972 and more recent publications such as the Chicago Homer, ${ }^{7}$ Suda Online, ${ }^{8}$ Inscriptions of Aphrodisias ${ }^{9}$ and Roman Tripolitania, ${ }^{10}$ to name but a few. These are primarily textbased sources whether that text is found on papyrus, parchment, paper or stone. This also is in a context where Classical Greek and Latin are the two heritage languages of European and Western culture, and Greco-Roman culture forms the foundation of European (and by extension North American) cultural heritage, literature and philosophy. This foundation and reverence is clearly manifest when looking at the canon of literature and the architectural design of many public buildings such as museums and galleries with their columns and porticos mimicking those of Athens and Rome. ${ }^{11}$

\section{Cultural and Linguistic Diversity}

Looking back to our earliest writings in Europe and the earliest surviving complete work in Greek literature from the so-called 'Father of History', Herodotus of Halicarnassus (approx. 484-425 BC), we read in the very first paragraph of the first page of his Histories the justification for this work: that human achievement not be forgotten and that the deeds of the Greeks and barbicans should have their glory and particularly that we should know 'why' they fought each other (adapted from De Selincourt (trans) 1972). He uses the term 'barbarian' in the same way that Chinese understand 'foreigner' - to Herodotus anyone that did not speak Greek was a barbarian as their speech sounded like that of sheep. He moves on to account for the origins of the quarrel that began the enmity between East and West (Asia and Europe), and he arrives at conflicted accounts. The scene is set, however, for the long-running conflict between East and West; he is, of course, talking about Greece (Europe) and Persia (or more particularly the Medes as Asia, built on the relatively understudied empire of Cyrus the Great). There is a gulf in understanding between the two. They speak different languages and have different cultures and customs while each, he tells us, 'without exception believes his own native customs [...] to be the best. [...] Pindar was right when he called [custom] king of all' (De Selincourt (trans) 1972, 3:38). The Histories culminates with the invasion of Greece firstly by Darius and then by his son Xerxes and their defeat at the hands of an

\footnotetext{
5 TLG http://stephanus.tlg.uci.edu.

${ }^{6}$ LGPN http://www.lgpn.ox.ac.uk.

7 Chicago Homer http://homer.library.northwestern.edu.

8 Suda Online http://www.stoa.org/sol.

9 Inscriptions of Aphrodisias http://insaph.kcl.ac.uk.

10 Inscriptions of Roman Tripolitania http://inslib.kcl.ac.uk/irt2009.

11 See the British Museum in London and the Library of Congress in Washington DC as two striking examples.
} 
alliance of Greek city states. Whether Herodotus actually travelled beyond the wider Greek world or collected together stories gathered from sailors in the ports of Halicarnassus or Piraeus is not a discussion to have here but from these accounts, whatever the source, the further East, we read in Histories, the more mysterious are the peoples and their customs. Whatever the truth, it is clear that differences in language and culture lead to difference in understanding.

An Anglo-centric critique of the $\mathrm{DH}$ is nothing new and was made well by Fiormonte in his 2012 article 'Towards a Cultural Critique of the Digital Humanities'. He starts with the perceived tension between methodological differences before moving on to the geopolitics which he claims is to be found endemic in our field as evidenced by the dominance of such pervasive systems as ASCII code (American Standard for Information Exchange) and the domain name system (administered by ICANN). The same is of course true for HTML and the ubiquitous XML, the latter particularly having a pronounced linguistic bias (difficulties with accented characters and right-to-left scripts) as well as the English-based TEI guidelines. As I explain to students when giving visiting lectures and talks overseas, English is the language of the Web and of digital publishing. It is, therefore, an additional incentive to learn English for anyone wanting to work in the myriad of Internet industries regardless of whether or not they study or train in an English-speaking environment. The counter side to this is, of course, that working in these industries does not incentivize English speakers to develop other language skills. This dominance of the English language is, of course, not only an issue for the digital humanities as a trip to the Fudan Library will doubtless reveal the wealth and spread of journals and magazines it holds, covering many fields and disciplines for which the major and most prestigious publications are often in English.

For a European example, in Italy Informatica Umanistica has long been established at the University of Pisa ${ }^{12}$ and elsewhere. In my former institution, I was very pleased to have as colleagues a former lecturer and a former student from that programme (Elena Pierazzo now at Grenoble and Raffaele Viglianti now at MITH), but we hear little about the activities of the Italian Informatica Umanistica in mainstream DH publications; with the exception, perhaps, of Fiormonte quoted above and Geoffrey Rockwell, also included in this publication, drawing our attention to the importance of Tito Orlandi and others. This is despite the continuing work of the very research centre founded by Roberto Busa being carried out on the Index Thomisticus Treebank at CIRCSE at the Università Cattolica del Sacro Cuore, Milan. ${ }^{13}$ Colleagues at the UCL Centre for Digital Humanities (UCLDH), Julianne Nyhan and Andrew Flinn, have worked on uncovering some of the lesser known histories of the development of the digital humanities, including interviewing

\footnotetext{
12 Informatica Umanistica: University Pisa https://www.unipi.it/index.php/lauree/corso/10456.

13 Centro Interdisciplinare di Ricerche per la Computerizzazione dei Segni dell'Espressione (CIRCSE) http://centridiricerca.unicatt.it/circse-home?rdeLocaleAttr=en.
} 
Orlandi, for their (2016) volume Computation and the Humanities. It is pleasing to see the new journal of the Italian Association of Digital Humanities, Umanistica Digitale, online although this seems to be mostly in English. ${ }^{14}$

\section{Objects of Study}

This bias is not restricted to language but also concerns the materials of our study. From the early days of computational scholarship in the humanities, text has always been the fundamental material for study as evidenced by the Index Thomisticus, through the TLG and many other publications. Looking, however, at the research projects at my own DH centre (UCLDH), we now see a much greater variation in source material and data. The Nyan and Flinn volume mentioned earlier gathers together oral history interviews to push 'forward the current boundaries of scholarship on the history of DH' and questions the previous narratives (Nyhan and Flinn 2016, p. 277). There are projects using nondestructive imaging technology to uncover texts otherwise not visible, such as on an Egyptian coffin lid and the papyri used as filling ${ }^{15}$; an online camera capturing viewers' reaction to seeing the auto-icon of Jeremy Bentham; computer algorithms to assist reassembling fragments of wall paintings; handwriting recognition; Open Educational Resources; user log analysis; and many more. ${ }^{16}$ The objects of our research within $\mathrm{DH}$ are changing.

Even within the area of textual scholarship, digital humanities methodologies have opened up new opportunities to study texts in different ways. Examples from two of my PhD students illustrate this well. Greta Franzini, ${ }^{17}$ on the editorial board of Umanistica Digitale, began her doctoral research to create a digital edition of a medieval Latin manuscript, being the oldest surviving copy of St. Augustine's De Civitate Dei and held in the scriptorium at her hometown of Verona. This project has morphed into much more and now includes best practice in the field of electronic editing, user studies and requirements, as well as recommendations for the production of digital editions of texts. Part of this research has been to create a detailed catalogue of extant digital editions of texts, and this included mapping the institutions involved; the results clearly demonstrate the Western-European and US focus on such production (see Fig. 1).

\footnotetext{
14 Umanistica Digitale https://umanisticadigitale.unibo.it.

15 UCL Advanced Imaging Consultants http://blogs.ucl.ac.uk/dh/2018/01/12/ucl-advanced-imagingconsultants-uclaic-undertake-imaging-projects-on-a-range-of-fascinating-heritage-materials.

16 UCLDH Research Projects http://www.ucl.ac.uk/dh/projects.

17 Greta Franzini http://www.gretafranzini.com.
} 


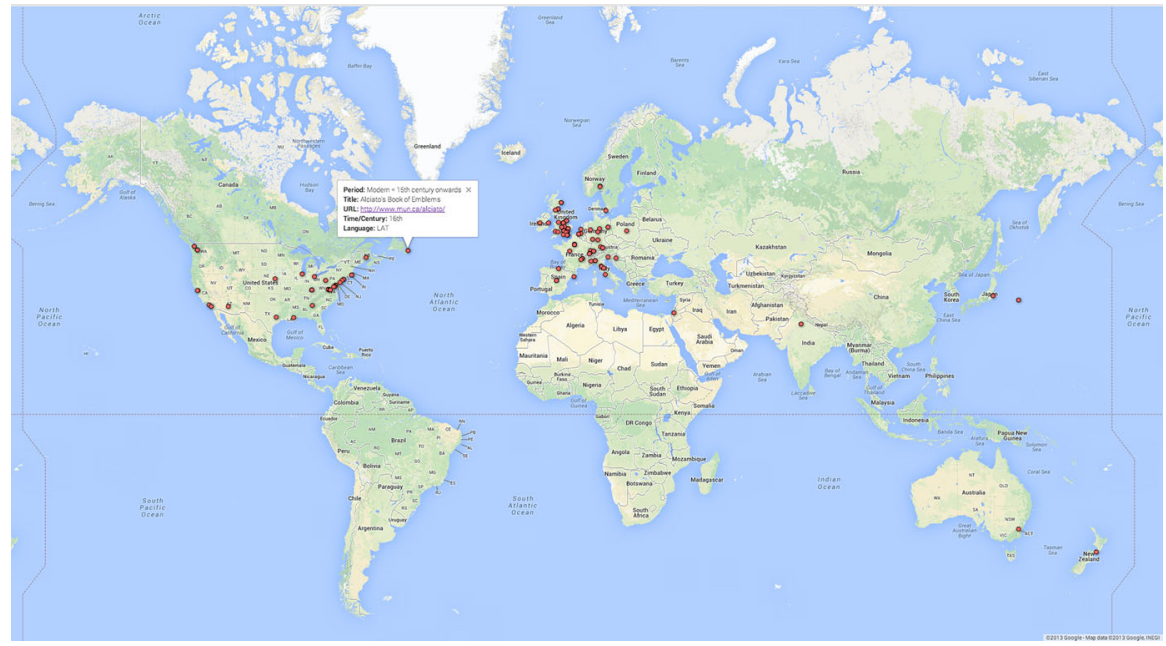

Fig. 1 Screenshot of the map visualization of editions present in the Catalogue of Digital Editions. Note: this is at the time of writing: 2014. (Franzini et al. 2016, p. 170)

[...] the reader will notice a shortage of, for example, Asian and Arabic editions as we work through those in the catalogue. Nevertheless, digital editions appear to be a Western phenomenon, led by the United States and the United Kingdom, two of the wealthiest and most influential countries in the world, both economically and politically (Franzini, Mahony and Terras 2016, p. 172).

In this study, $65 \%$ of the projects are Anglo-American; that is 123 out of the total of 187 editions recorded.

Moreover, it is necessary to remember that the major associations and portals in the digital humanities field are based in the USA and the UK; as well as this, historically, the major journals published in DH are primarily English language publications. ${ }^{18}$ As a result, Chinese digital editions and any others in a non-Latin script were not included in the catalogue because of the language barrier which further serves to accentuate any bias (Franzini et al. 2016) (Fig. 2).

Another of my PhD students, Jin Gao, ${ }^{19}$ is researching the intellectual and social structures of DH with research methodology primarily (so far) based on citation and social network analysis. At the ADHO DH2017 conference, Gao presented her preliminary results showing the clustering of topics based on her co-citation analysis of the major DH journals: Computers and the Humanities, Digital Scholarship in the Humanities (formerly known as Literary and Linguistic Computing) and Digital

\footnotetext{
18 Among others, the Association for Computers and the Humanities (ACH); Alliance of Digital Humanities Organizations (ADHO); the European Association for Digital Humanities (formerly ALLC); arts-humanities.net; DHCommons; Digital Humanities Now; Humanities, Arts, Science, and Technology Advanced Collaboratory (HASTAC) and The Humanities and Technology Camp (THATCamp).

19 Jin Gao http://www.ucl.ac.uk/dis/people/gao.
} 


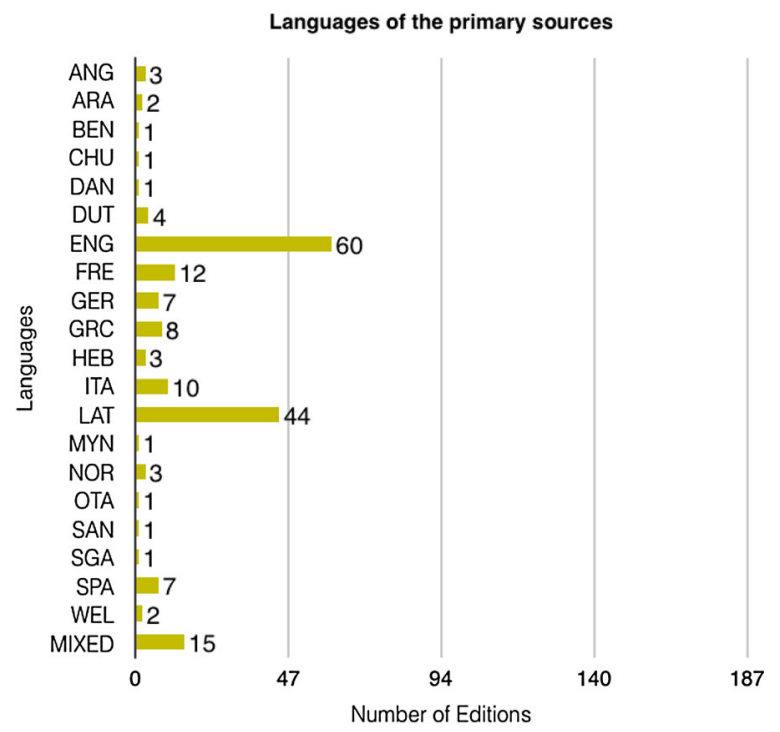

Fig. 2 Languages of the primary sources presented in the Catalogue of Digital Editions. Note that this is at the time of writing: 2014. (Franzini et al. 2016, p. 176)

Humanities Quarterly; these are all in the English language. ${ }^{20}$ At a recent seminar in the Department of Information Studies at UCL, Gao presented her latest research which focused on visualizing the DH community through the connections made in Twitter; effectively, this represents an analysis of who is connected to whom by their patterns of re-tweeting content on the microblogging platform that is used extensively by members of the DH community. Interestingly, this also revealed edge clusters in languages other than English, with the largest being French, followed by German (also including Dutch contributors using German rather than their native Dutch) and then Spanish. The lack of Italian is curious given the stature of the late Father Busa and the longevity of Informatica Umanistica but perhaps they are tweeting in English or one of the other European languages. It is important to note that these edge clusters are determined by the language of the tweets rather than the home nation of those posting them, although it was also found that these individuals do sometime post tweets in English as well, presumably when entering into discussion and engaging with English language Twitter posts. The main point here is that although the original source material is text, in some form or other (citations in journals or Twitter postings), it is being interrogated using visualization methodologies to further understand the field's intellectual structures rather than any close reading of the texts themselves. Moreover, we can identify other languages being used within a primarily English-speaking medium.

Again, however, we are looking at an Anglo-focus here and there are, I am sure, many other DH microblogging discussion groups out there in many different languages and on many different platforms. China, for example, has the ubiquitous

\footnotetext{
${ }^{20}$ DH2017 abstracts https://dh2017.adho.org/program/abstracts.
} 
WeChat and the $\mathrm{DH}$ groups that I am aware of and a member of are Digital Humanities Group 1 (数字人文1群IDH Group1), Digital Humanities Group 2 (数字 人文2群IDH Group2), with 500 and 224 members (approximately 600 unique individuals), respectively, at the time of writing, and DH Global (for non-Chinese speakers with 15 members at this time) and doubtless there are many others elsewhere. It is notable also that the names of DH Group 1 and DH Group 2 were changed to include the Latin characters very soon after allowing me to join.

Nevertheless, despite the clear language issues, from this, we can also see that digital humanities methodologies and techniques are allowing us to ask new and interesting questions of text that were not possible previously without the intervention of computational analysis.

The scope and variety of digital humanities research is, of course, much broader; for example, at UCLDH, as noted above, we have projects that make use of digitization, the visualization of materials, text mining, crowdsourcing and many varied methodologies. Although the source data are still often in the form of text (the letters of Jeremy Bentham, the British Library corpus of digitised newspapers, census records from the National Archives, etc.), we are doing new and innovative research using these materials. In addition, the sources also now include oral histories and cultural heritage artifacts. ${ }^{21}$

\section{Moving Beyond}

Just as the objects of DH study are moving beyond a focus on the reading of written text, so too they are now moving beyond their linguistically imposed geographical boundaries. The Alliance of Digital Humanities Organizations (ADHO) conference no longer simply alternates between Europe and North America, with DH2015 in Sydney and DH2018 to be hosted at the National Autonomous University of Mexico (UNAM), Mexico City. ADHO itself has become more global with membership extending to DH Associations in Australasia and Japan ${ }^{22}$ :

- The European Association for Digital Humanities (EADH)

- Association for Computers and the Humanities (ACH)

- Canadian Society for Digital Humanities/Société canadienne des humanités numériques (CSDH/SCHN)

- centerNet

- Australasian Association for Digital Humanities (aaDH)

- Japanese Association for Digital Humanities (JADH)

- Humanistica, L'association francophone des humanités numériques/digitales (Humanistica)

centerNet which describes itself as, 'an international network of digital humanities centers formed for cooperative and collaborative action to benefit

${ }^{21}$ UCLDH Research Projects http://www.ucl.ac.uk/dh/projects.

${ }^{22}$ Alliance of Digital Humanities Organizations (ADHO) http://adho.org. 


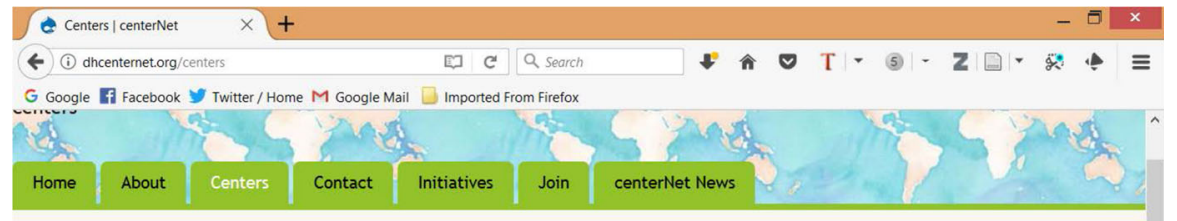

\section{Centers}

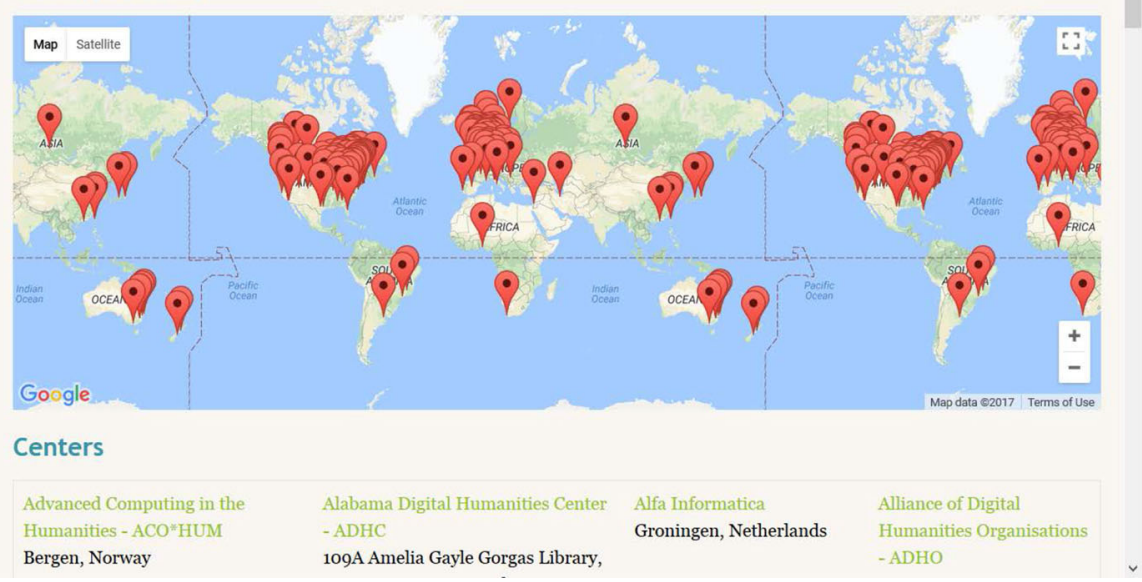

Fig. 3 centerNet, Centres map http://dhcenternet.org/centers (November 2017)

digital humanities and allied fields [...]', pulls together DH centres internationally. ${ }^{23}$ Their map, just as the one above (Fig. 1, Franzini, Mahony and Terras. 2016, p. 170) also shows a preponderance of Western Europe and North America with a few outliers (Fig. 3). ${ }^{24}$

This online map from centreNet is also very similar to the one recorded in the infographic (Fig. 4) published by Melissa Terras, then Director of UCLDH, to quantify the extent of DH activities globally in 2012 (Terras 2012). According to these graphics, the spread of DH centres in the East has changed little in the intervening 5 years; one has gone missing from South Korean and one added at Hong Kong (to identify the cause or to see whether this results from a possible error in the data would take further research beyond the scope of this article).

In East Asia, the centreNet map (Fig. 3) indicates DH centres in Tokyo and Kyoto in Japan, Taipei in Taiwan, and one in Hong Kong. What is missing is a connection here with mainland China.

Notwithstanding this, 2016 saw the first Chinese DH Forum at Peking University (PKU), Crossing Boundaries and Engaging Communities: Digital Humanities under Global View, with the second in 2017, Interaction and Coexistence: Digital

\footnotetext{
23 centerNet http://dhcenternet.org.

24 centerNet: map of the registered centres http://dhcenternet.org/centers.
} 


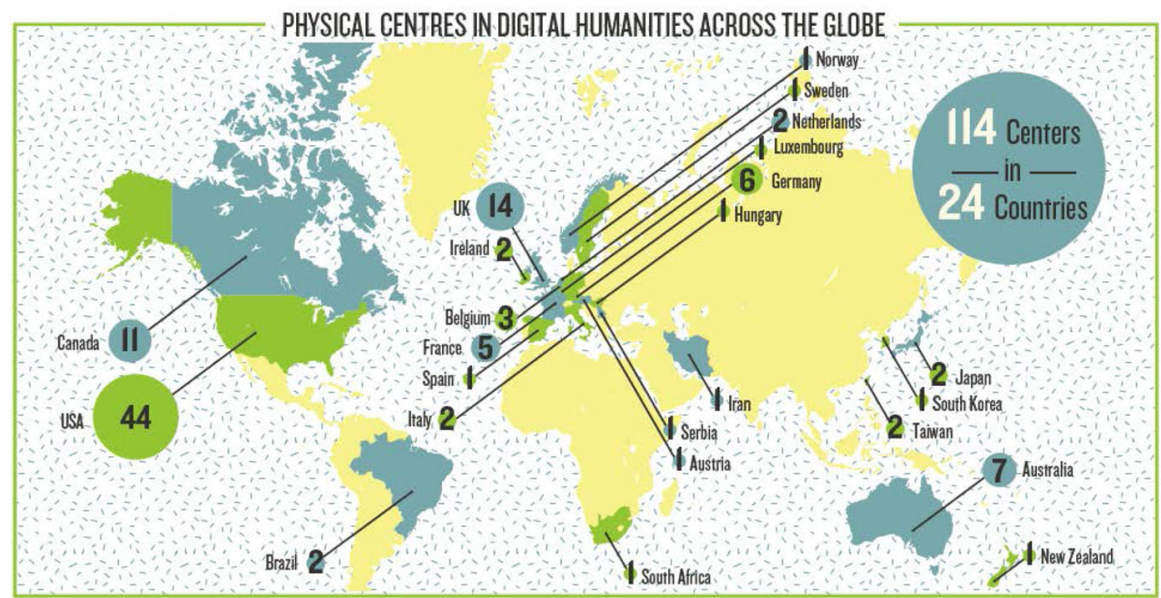

Fig. 4 Global DH centres (detail from Terras 2012)

Humanities and Historical Research. ${ }^{25}$ At the time of writing, we have just seen the Call for Papers for the third DH Forum at PKU circulated, Incubation and Application: How Digital Humanities Projects Cater to Academic Needs. The first Chinese DH centre was established at Wuhan in 2011 (although apparently not registered with centreNet), with another set up this year at Nanjing (I have already met with the Director of the Wuhan Centre and hope to visit both centres in 2018 as part of my \#ChineseDH networking activities); DH was one of the topics for the 2017 Fudan Conference, Cross-cultural, Cross-group and Comparative Modernity Conference, from which this publication derives, and the International Symposium on Library and Digital Humanities (ISLDH) was held at Shenzhen in December 2017.

As these maps demonstrate, there are a number of DH centres listed in centerNet clustering around the East Asian Pacific rim: Hong Kong, Taiwan and Japan. Perhaps as a result of cross-Pacific migration and/or trading links, there seems to be an ever-growing interest in collaborative DH projects in the USA that focus on Chinese literature and culture: the China Bibliographic Database Project ${ }^{26}$ and the Chinese Text Project, ${ }^{27}$ both based at Harvard along with the East Asia DH Lab. ${ }^{28}$ The Harvard/China connection can, of course, be traced back to John King Fairbank, the first Director of the Center for Chinese Studies based there and subsequently named after him, and his pioneering work on Chinese history and

\footnotetext{
25 The first DH forum at PKU http://pkunews.pku.edu.cn/xwzh/2016-05/25/content_293906.htm; The second DH Forum held at PKU http://english.pku.edu.cn/news_events/news/focus/5944.htm.

26 China Bibliographical Database Project (CBDP) https://projects.iq.harvard.edu/cbdb and.

27 Chinese Text Project http://ctext.org.

28 East Asia DH Lab http://guides.library.harvard.edu/c.php?g=608708\&p=4279908.
} 
culture. $^{29}$ A quick search of the Web brings up others including the DH Asia 2018 Summit being held at the Stanford Humanities Center. ${ }^{30}$

In London, 2015 saw the official opening by President Xi Jinping, President of the People's Republic of China, of the UCL Institute of Education, Confucius Institute, 'supporting the teaching and learning of Mandarin Chinese and the study of China across other areas of the curriculum'. ${ }^{11}$ At King's College London, there is the Lau China Institute for the study of contemporary China. ${ }^{32}$ While writing this article, I received a PDF via the 'Digital Humanities Group 1' WeChat group of a new publication in the journal Digital Scholarship in the Humanities, examining text reuse in early Chinese literature (Sturgeon 2017b). There is clearly much active Western research activity in this rich field.

Closer to my own interests, I co-organize the Digital Classicist Summer Seminar series supported by the Institute of Classical Studies, School of Advanced Study, at Senate House, London. In our 2017 series, we invited Donald Sturgeon from Harvard to present a paper entitled 'Crowdsourcing a digital-library of pre-modern Chinese' with a focus on the Chinese Text Project mentioned above. ${ }^{33}$ This was well attended and particularly by colleagues from the British Library working on the Chinese manuscript collections held there. Of more note, the British Library is a partner institution for the International Dunhuang Project: The Silk Road Online (IDP). ${ }^{34}$ This project pulls together disparate collections of artifacts and manuscripts originally held at Dunhuang and now dispersed internationally, as well as of other heritage sites along the Eastern Silk Roads. This multinational project has stated aims to engage in the conservation of the original documents and artifacts, cataloguing and research, the systematic digitisation of the material to allow access that would not otherwise be possible, as well as the all-important education and outreach to bring this collection to a wider audience. ${ }^{35}$ These types of projects stimulate the interest in and so the scholarship on this important cultural area. They in turn acknowledge the huge debt that Europe and the West owe to Chinese culture, technology, innovation and scholarship, for example, the recently screened BBC Four documentary, The Silk Road ${ }^{36}$, and also scholarly print publications such as Frankopan (2017). The IDP online project publishes in a range of languages (English, Chinese, Russian, Japanese, German, French and Korean) or at least when the various hosting sites are available. These languages make the content available beyond the immediate confines of either the anglophone world or the Mandarin one. This is an exemplar for the appropriate and effective dissemination of scholarship, making the research outputs and other material available in a range of languages,

\footnotetext{
${ }^{29}$ Fairbank Center for Chinese Studies http://fairbank.fas.harvard.edu/.

30 DH Asia 2018 Summit http://shc.stanford.edu/events/digital-humanities-asia-2018-summit.

31 IOE Confucius Institute http://www.ucl.ac.uk/ioe/departments-centres/centres/ioe-confucius-institutefor-schools.

32 Lau China Institute https://www.kcl.ac.uk/sspp/departments/lci.

33 Sturgeon http://www.digitalclassicist.org/wip/wip2017-02ds.html.

34 IDP http://idp.bl.uk.

35 IDP Activities http://idp.bl.uk/pages/about_activities.a4d.

36 BBC The Silk Road http://www.bbc.co.uk/programmes/p03qb130.
} 
makes them accessible to a far wider audience and does not restrict the engagement or outreach to a single language-based audience.

At UCLDH, we have had students working at the British Library on the IDP and writing dissertations relating to that project, on the importance of the Silk Roads and the impact that publishing otherwise unobtainable original source material online has and how it benefits research in that area. We also have our own project, Bridge to China, which aims to further the understanding of all aspects of the Chinese speaking world. ${ }^{37}$ UCL, more widely and as a linguistic centre, ${ }^{38}$ has been partnering attempts to address the language issues and limitations of Internet domain names, with their limited character set, as a partner organization in ICANN'S development of the New Generic Top-Level Domains, particularly with regard to Chinese (Han), Japanese and Korean characters. ${ }^{39}$

Language initiatives are particularly welcome in the UK as we are notoriously bad at learning languages, despite language learning being compulsory at Primary School level, and as English had become such an international language, there is generally not the incentive to do so. ${ }^{40}$ Lack of language acquisition is not the only potential issue when it comes to lack of linguistic diversity. Greg Crane points to the problematic nature of the loss of the rich linguistic diversity previously found in the USA (particularly German although with an acknowledged rise in Spanish) (Crane 2015a).

\section{Widening the Possibilities}

East Asia is not the only linguistically under-represented area in DH. The closing keynote of the ADHO DH 2013 conference held at the University of NebraskaLincoln USA was given by Isabel Galina Russell, an Honorary Research Fellow at UCLDH where she completed her $\mathrm{PhD}$, now working at the Institute for Bibliographic Studies at UNAM, Mexico. In her keynote, 'Is There Anybody Out There? Building a global Digital Humanities community', Galina raises many of the questions touched on above (Galina 2013). Galina asks, 'who are we?' in Digital Humanities and we both share a similar view: DH is a community (more on that below). However, there are problems here which she articulates well:

One of the things that characterizes DH I think is that the community has worked very hard towards building the DH community. And most of this work has come from enthusiastic and generous scholars who have given much of their time to developing it. [...] This community has traditionally viewed itself, as with the conference, as welcoming and open. Collaboration and

\footnotetext{
37 Bridge to China https://wiki.ucl.ac.uk/display/Chinese.

38 'UCL and SOAS (the nearby School of Oriental and African Studies) together form the world's leading centre of linguistic expertise, teaching and researching more than 80 languages' http://www.ucl. ac.uk/ah/domain-names/leading-centre.

39 UCL Domain Names http://www.ucl.ac.uk/ah/domain-names.

${ }^{40}$ UK National curriculum https://www.gov.uk/government/publications/national-curriculum-inengland-languages-progammes-of-study.
} 
cooperation are seen as specific traits of $\mathrm{DH}$ that differentiate it from the more "lone-scholar" traditional humanist. It seems to be that openness and a desire to work with others is fundamental to the way we think of ourselves. And yet, over the past few years this community has become aware that this isn't so open, universal as it thought it was (Galina 2013).

The field of digital humanities has arguably been built on openness and a sense of community but has historically excluded much of the world by its anglophone preponderance and focus on text-based scholarship. This, as Galina says, has been pointed out over time but has only more recently 'become more of a mainstream discussion' (Galina 2013). It is argued in this article that perhaps a self-conscious anxiety over the value and importance of the field (if it can indeed be called that) of digital humanities has got in the way of our reflection on what it is that we do and why we do it. As an educator, this is a task that we often give our students in their assignments and certainly something that we (in the UK) write into module and programme proposals; reflective practice is, or should be, part of the training of our students (the next generation of practitioners) and yet, under all the pressures of academia, we perhaps find little time for that ourselves. Experience show that this is not limited to DH but often the case across the wide range of disciplines found in academia.

The Mexican DH has an established organization Red de Humanidades Digitales $^{41}$ with its material published in Spanish. Spanish is also a European language, and although there are variations specific to Mexico, it is still a European Romance (Indo-European) language that has grown from Latin Vulgar, the common and spoken language (as opposed to the Classical Latin of literature and poetry) of much of Europe during and after the time of the Roman Empire and throughout the Mediterranean geographic area. It has a common root and heritage with many other European languages but because of the predominance of the English language, particularly in international journals, publication in English is needed to ensure disseminated and engagement with knowledge production. This is true also with Spanish universities and their doctoral degrees. My own experience of presenting at events in Mexico has involved them supplying live translators, for my benefit rather than anyone else's, as I have often been the only non-Mexican presenter. ${ }^{42} \mathrm{My}$ attempts at pronunciation prompted polite amusement from my hosts as I attempted to apply my best Anglo-Andalusian accent to Mexican terms, names and titles.

For guest talks and workshops delivered in China, I have a translator plus the main text on any content slides is translated into Mandarin by my Chinese students. Where possible, I just use images in slides as these need no translation and the language is international. At my home institution, in accordance with our regulations, my teaching slides are made available for the students prior to classes; this was originally to help students with reading difficulties (e.g. dyslexia) but now more so for the non-native speakers in my classes, who make up the majority, to allow them to investigate unfamiliar words and technical terms beforehand. As a

\footnotetext{
${ }^{41}$ Red de Humanidades Digitales http://www.humanidadesdigitales.net.

42 For example, at the University of Guadalajara (Mahony 2015).
} 
lecturer, I quickly learned to remove all traces of sarcasm and irony from teaching material as feedback indicated that some students had thought that examples being held up for ridicule were there as exemplars of good or best practice. I had previously trained as a language teacher to adults and so routinely avoided jargon and colloquial expressions or culturally specific examples to illustrate points.

The dominance of the English language is, as above, a barrier to inclusivity to all who do not read or speak English. In DH, we now have GO::DH (Global Outlook:: Digital Humanities), which is a Special Interest Group (SIG) of ADHO with a purpose,

to help break down barriers that hinder communication and collaboration among researchers and students of the Digital Arts, Humanities, and Cultural Heritage sectors in high, mid, and low income economies [...] Its core activities are Discovery, Community-Building, Research, and Advocacy. ${ }^{43}$

ADHO, itself, also has the Multi-Lingualism and Multi-Culturalism Committee (MLMC), which is there to consult with its steering committee over questions of multiculturalism. The wide range of nationalities within this group can be seen from the list of representatives on their web page along with their protocols and policy documents for linguistic and cultural inclusion. ${ }^{44}$ In Europe, the EADH has an executive composed of members from a great number of countries, although I understand that English is generally spoken as the most common language. They have associate and partner organizations with $\mathrm{DhD}^{45}$ (German speaking), AIUCD ${ }^{46}$ (Italian), $\mathrm{DHN}^{47}$ (Nordic countries) and $\mathrm{CADH}^{48}$ (Czech). There are indeed linguistic diversity and multicultural inclusion although in a European and predominately English-speaking sphere.

These issues are not confined to DH but there seems to be justifiable concern in a field where there is a drive for inclusiveness rather than exclusion. This is arguably one of the reasons why we struggle 'not' to define the field of DH, which has been a distinct policy at UCLDH. Once you give definitions, you are erecting barriers and fences; if you define what it is that explicitly constitutes DH, you are also saying what is not $\mathrm{DH}-$ you are excluding people. We prefer to think of ourselves as selfdefining. We are part of the DH community because we think and say that we are; in other words, we self-identify with the field. We also see ourselves as a 'community' and self-consciously describe our field as such (Mahony 2017). Language is indeed a barrier to inclusion and inclusiveness, and we must endeavour to address this and other issues such as an apparent lack of reflection on what it is that we do and why we do it.

Galina suggests some simple ways to make things more accessible to nonEnglish speakers such as having more translations of published research outputs and

\footnotetext{
43 GO::DH http://www.globaloutlookdh.org.

${ }^{44}$ MLMC https://adho.org/administration/multi-lingualism-multi-culturalism.

45 DhD http://dig-hum.de.

46 AIUCD http://www.aiucd.it.

47 DHN http://dig-hum-nord.eu.

48 CADH http://czdhi.ff.cuni.cz/en/about.
} 
project reports with the resulting costs being built into funding proposals (Galina 2013). Having more international conferences, such as the one in Fudan, and the movement of the major conferences outside of the anglophone zone would go some way to addressing this. Without doing these things, we are restricting our participants and our audience, and so limiting the global reach of our DH community.

There are, of course, also issues of connectivity and computing infrastructure which hamper our wider connections. These are not discussed in this article, other than to note that there are great regional differences within the UK itself without having to cross any political borders. The so-called Digital Divide has not yet been resolved here in a technologically developed nation. In China, where there is a much faster growth in Internet penetration, the gap appears to be closing with the spread of phone networks (the most popular way to connect to the Internet in China) (Statista 2018), although there is still a clear gap between urban and rural areas which the government is planning to address. ${ }^{49}$ In the UK, the drive is still for highspeed fibre optic cables, although full coverage in even such a small country is still limited with a similar gap between urban and rural areas, with the greatest coverage in the more populated and affluent areas. ${ }^{50}$

\section{Conclusion}

Returning to the main topic of cultural diversity and the digital humanities, as shown by the examples above, we are now seeing within DH an ever-growing interest in exploring culture and heritage more widely. Geographic inclusion, however, does not necessarily equate to scholarly inclusion, particularly if language is a barrier to that inclusiveness. This is an issue for the principal DH journals, other DH publications, and calls for conference papers within the global DH sphere. For the ADHO international DH conference in 2018, we have the call for papers available and circulated in a variety of languages (German, English, Spanish, Italian and Portuguese) as well as the conference itself being bilingual.

The conference will be officially bilingual in Spanish and English, so we invite proposals for presentations particularly in these languages, as well as in the other languages for which we have a sufficient pool of peer reviewers (German, Italian, French and Portuguese, the latter an important language community of our host region). ${ }^{51}$

This is pleasing to see and not too unexpected as it will be held in Mexico City at UNAM with Red de Humanidades Digitales as one of the hosting organizations and Galina Russell as one of the local conference organizers.

Another important issue that cannot be overlooked is that of institutional support; a digital humanities centre requires this support along with a coherent management

\footnotetext{
$\overline{49}$ China Daily http://usa.chinadaily.com.cn/china/2017-04/20/content_29006036.htm.

50 GOV.UK https://www.gov.uk/guidance/broadband-delivery-uk.

51 DH2018 Call for Papers (CfP) https://dh2018.adho.org/en/cfp.
} 
policy. It can also find itself being constantly asked to justify its existence and whether or not it represents 'good value' for the resources (staff time and funding) that it receives. Within rigid university structures, it is easy to say that interdisciplinary practice is encouraged but as we all find out to our cost, it is often difficult to achieve. Beyond the institutional barriers imposed by Schools and Faculties, there are also the disciplinary ones which bring with them their own logistical, practical and inter-personal ones too. These often revolve around the management of projects, funding opportunities, recognition for the work done and publishing venues (Terras 2010). In the introduction to Debates in the Digital Humanities, Matthew Gold also expresses this but in a different way, describing DH as 'a field in the midst of growing pains as its adherents expand from a small circle of like-minded scholars to a more heterogeneous set of practitioners who sometimes ask more disruptive questions' (Gold 2012). This 'disruption' is another potential cause of tension when entering into collaborations with more established disciplinary areas. Institutional support is needed to facilitate interdisciplinary working, to provide support for DH centres and their activities, as well as allowing practitioners to engage in international projects and events; budgets for travel, conference attendance, publication, and now also for translation must be part of long-term institutional strategic vision.

As an academic field, DH has come a long way in a relatively short time but we still have much to do to achieve the openness, sense of community and inclusiveness that we aspire to. We need to have more conversations with DH groups beyond the anglophone sphere and the conference in Fudan, that prompted this article, and that in Shenzhen (mentioned above) have given the opportunity for and facilitated several such conversations. Chinese DH centres and research groups in libraries such as PKU and Shanghai offer a welcome and hospitality to Western visitors. The challenge is for us in the Western anglophone sphere to be equally welcoming and willing to engage with researchers and practitioners outside of our echo-chamber and to reach out more widely. Otherwise, we are destined to meet, greet and discuss our topics of interest and research only with those that we already know.

\section{Coda}

Just as the artefacts we produce are the results of cultural influences, so too are the writings, our cognitive processes, and how we view and understand the world around us. This article has also drawn on my own very limited research into crosscultural teaching, examining some of the issues that become apparent when working across disciplinary and ethnic boundaries; it also considers some of the growing number of collaborative DH projects that focus on Chinese literature and cultural heritage. Restricting our cultural perspective is restricting our field; we all learn from each other and inclusion benefits us all. And without this, it is those English speakers who have no other language that stand to lose the most. Greg Crane expresses this well: 
Now, English has emerged as a de facto lingua franca - with of those of us who grew up speaking English losing the most, insofar as the widespread use of English makes it easy for us to ignore the importance of language and to avoid the challenge of mastering languages other than our own. No one would benefit more from a commitment to linguistic diversity than speakers of English (Crane 2015b).

Open Access This article is distributed under the terms of the Creative Commons Attribution 4.0 International License (http://creativecommons.org/licenses/by/4.0/), which permits unrestricted use, distribution, and reproduction in any medium, provided you give appropriate credit to the original author(s) and the source, provide a link to the Creative Commons license, and indicate if changes were made.

\section{References}

Bodard and Mahony eds. 2008. "Though much is taken, much abides": Recovering antiquity through innovative digital methodologies' Digital Classicist special issue, Digital Medievalist 4.

Crane, Gregory. 2015a. 'Resisting a monocultural (digital) humanities' https://docs.google.com/ document/d/1NovwutuBpA0yN9UiBjvz_tscAvzs6EXRsJrZiSN2-VQ. Accessed 29 Jan 2018.

Crane Gregory. 2015b. 'The Big Humanities, National Identity and the Digital Humanities in Germany'. http://www.dh.uni-leipzig.de/wo/the-big-humanities-national-identity-and-the-digital-humanitiesin-germany. Accessed 29 Jan 2018.

De Selincourt, Aubrey. 1972. (trans) Herodotus The Histories. Penguin.

Fiormonte, Domenico. 2012. 'Towards a Cultural Critique of the Digital Humanities', Historical Social Research, Vol. 37 No. 3, 59-76. Reprinted in: Debates in the Digital Humanities 2016, eds Matthew Gold and Lauren Klein (eds) University of Minnesota Press.

Fiormonte, Domenico. 2015. 'Towards monoculture (digital) humanities?' Infolet: Cultura e critica dei media digitali :7. https://infolet.it/2015/07/12/monocultural-humanities. Accessed 29 Jan 2018.

Frankopan, Peter. 2017. The silk roads: A new history of the world. London: Bloomsbury Publishing.

Franzini, Greta, Simon Mahony, and Melissa Terras. 2016. 'A Catalogue of Digital Editions.' In Digital Scholarly Editing: Theories and Practices, eds. Elena Pierazzo and Matthew Driscoll, 161-182. Open Book Publishers.

Galina Russell, Isabel. 2013. 'Is There Anybody Out There? Building a global Digital Humanities community', Humanidades Digitales http://humanidadesdigitales.net/blog/2013/07/19/is-thereanybody-out-there-building-a-global-digital-humanities-community. Accessed 29 Jan 2018.

Gold, Matthew. 2012. 'Introduction: The Digital Humanities Moment'. In Debates in the Digital Humanities, ed. Gold, Matthew, IX-XVI. University of Minnesota Press.

Mahony, Simon. 2015. University of Guadalajara 'Reflections on knowledge production within the framework of UK academic institutions. http://www.udg.mx/es/noticia/redes-sociales-generannuevas-dimensiones-de-ensenanza. Accessed 29 Jan 2018.

Mahony, Simon. 2017. 'The Digital Classicist: building a Digital Humanities Community', Digital Humanities Quarterly 11:3. http://www.digitalhumanities.org/dhq/vol/11/3/000335/000335.html. Accessed 29 Jan 2018.

Meester, Wim. 2013. 'Towards a comprehensive citation index for the Arts \& Humanities' Research Trends 32. https://www.researchtrends.com/issue-32-march-2013/towards-a-comprehensivecitation-index-for-the-arts-humanities. Accessed 29 Jan 2018.

Nyhan, Julianne and Flinn, Andrew. 2016. Computation and the Humanities: Towards an Oral History of Digital Humanities, SpringerOpen.

Rockwell, Geoffrey. 2007. 'An alternate beginning to humanities computing?' Theoretica.ca.

Statista 2018 'Mobile phone internet user penetration in China from 2015 to 2022' https://www.statista. com/statistics/309015/china-mobile-phone-internet-user-penetration. Accessed 29 Jan 2018.

Sturgeon, Donald. 2017a. 'Crowdsourcing a digital library of pre-modern Chinese' http://www. digitalclassicist.org/wip/wip2017-02ds.html. Accessed 29 Jan 2018.

Sturgeon, Donald. 2017b. Unsupervised identification of text reuse in early Chinese literature. Digital Scholarship in the Humanities. https://doi.org/10.1093/lc/fqx024. 
Terras, Melissa. 2010. 'The Digital Classicist: Disciplinary Focus and Interdisciplinary Vision'. In Digital Research in the Study of Classical Antiquity, eds. Gabriel Bodard and Simon Mahony, 171-189. Ashgate.

Terras, Melissa. 2012. 'Quantifying Digital Humanities'. Infographic. UCL Centre for Digital Humanities. http://www.flickr.com/photos/ucldh/6730021199. Accessed 29 Jan 2018.

Simon Mahony is Director of the UCL Centre for Digital Humanities and Principal Teaching Fellow in Digital Humanities at the Department of Information Studies, University College London (UCL). His research interests are in the application of new technologies to the study of the ancient world, using new Web-based mechanisms and digital resources to build and sustain learning communities, collaborative and innovative working. He is a member of the UCL Student Recruitment Interest Group and recipient of support from UCL's Global Engagement Funding; chair of the New UCL Open Education Special Interest Group and on the Project Management Team and a member of the Project Board for the UCL Open Educational Resources (OER) Repository. He is also active in the field of distance learning and is a member of the University of London's Centre for Distance Education with an interest in the development of educational practice and the use of new tools to facilitate this. In addition, he is an Associate Fellow at the Institute of Classical Studies (School of Advanced Study, University of London) and one of the founding editors of the Digital Classicist. 